\title{
Melody, an ENU mutation in Caspase 3, alters the catalytic cysteine residue and causes sensorineural hearing loss in mice
}

\author{
Andrew Parker • Rachel E. Hardisty-Hughes • \\ Laura Wisby • Susan Joyce · Steve D. M. Brown
}

Received: 22 April 2010/Accepted: 8 November 2010/Published online: 30 November 2010

(C) The Author(s) 2010. This article is published with open access at Springerlink.com

\begin{abstract}
Progeny from the Harwell $N$-ethyl- $N$-nitrosourea (ENU) recessive mutagenesis screen were assessed for auditory defects. A pedigree was identified with multiple progeny lacking response to a clickbox test. Auditory brainstem response (ABR) analysis showed that homozygous mutant mice were profoundly deaf and the line was named melody. We subsequently mapped this mutation to a $6-\mathrm{Mb}$ region on chromosome 8 and identified a point mutation in melody that results in a C163S substitution in the catalytic site of Caspase 3, a cysteine protease involved in apoptosis. Melody fails to complement a null Caspase-3 mutant. Scanning electron microscopy (SEM) has revealed disorganised sensory hair cells and hair cell loss. Histological analysis of melody has shown degeneration of spiral ganglion cells in homozygote mice, with a gradient of severity from apical to basal turns. Melody heterozygotes also show evidence of loss of spiral ganglion neurons, suggesting that the C163S mutation may show dominant negative effects by binding and sequestering proteins at the active site. The melody line provides a new model for studying the role of Caspase 3 in deafness and a number of other pathways and systems.
\end{abstract}

\section{Introduction}

$N$-ethyl- $N$-nitrosourea (ENU) mutagenesis in the mouse has played an important role in identifying genes involved with a number of disease systems (Justice et al. 1999). By

A. Parker · R. E. Hardisty-Hughes - L. Wisby - S. Joyce · S. D. M. Brown $(\bowtie)$

MRC Mammalian Genetics Unit, MRC Harwell, Harwell Science and Innovation Campus, Oxfordshire OX11 ORD, UK

e-mail: s.brown@har.mrc.ac.uk carrying out wide-ranging phenotypic screens on mice carrying dominant and recessive ENU mutations, the functional effects of these mutations can be investigated (Brown et al. 2005; Hrabe de Angelis et al. 2000). The large-scale ENU mutagenesis program at MRC Harwell originally focused on dominant ENU mutations (Nolan et al. 2000), but it has expanded to screen mice for both dominantly and recessively inherited ENU mutations. Both phenotype-driven and gene-driven screens have helped identify many novel genes and alleles of existing genes involved with hereditary deafness and hearing loss (Brown et al. 2008).

Caspases are a group of cysteine proteases that play an essential role in programmed cell death (PCD) caused by apoptosis (Nicholson 1999). Caspases (cysteinyl aspartatespecific proteases) cleave substrates directly after an aspartic acid residue (Cohen 1997). Caspases share several structural similarities, all containing an $\mathrm{N}$-terminal prodomain followed by a large subunit approximately $20 \mathrm{kDa}$ in size (p20) and a small subunit of roughly $10 \mathrm{kDa}(\mathrm{p} 10)$. They are synthesised in a dormant form and require proteolysis by cleavage at specific aspartate residues to become mature (Earnshaw et al. 1999). There are at least 14 mammalian caspases, which are classified according to their function and structure. Group I, comprising Caspases $1,4,5,11,12,13$, and 14 , are known as the inflammatory caspases. Groups II and III are known as the apoptotic caspases. Group II caspases are the upstream initiator caspases that mediate the apoptotic response and consist of Caspases 2, 8, 9, and 10 and are activated by apoptotic signalling pathways. Downstream are the executioner caspases, Group III, comprising Caspases 3, 6, and 7, that are activated by the initiator caspases and represent the subclass of the caspase family that perform the proteolytic cleavage of apoptotic target proteins (Lavrik et al. 2005). 
Caspase 3 has been shown to be one of the main apoptotic executioner caspases and is either partially responsible or essential for the cleavage of many specific proteins during apoptosis (Cohen 1997).

We have identified a new deafness mutant melody from the ENU recessive screen at MRC Harwell. Homozygote melody mice display severe sensorineural hearing loss and hair cell and stereocilia bundle defects, similar to that reported for Casp3 knockout mice (Morishita et al. 2001; Takahashi et al. 2001). We have characterised in detail the effects of the mutation on the spiral ganglion and have revealed a gradient of severity across the cochlear turns as well as evidence of dominant effects in the heterozygote. We show here that the melody mutant carries a point mutation in Caspase 3 that changes the key catalytic cysteine residue to serine. This exact substitution is often employed in vitro for the study of Caspase-3 activity (Bose and Clark 2005; Feeney and Clark 2005; Gu et al. 1995; Kang et al. 2008; Van Criekinge et al. 1996) and as such melody provides a complementary in vivo model.

\section{Materials and methods}

Mice

All animals were housed and maintained in the Mary Lyon Centre at the MRC Harwell, under specific pathogen-free (SPF) conditions in individually ventilated cages, with environmental conditions as outlined in the Home Office Code of Practice. Animal procedures were carried out in line with Home Office regulations, and mice were euthanized by Home Office Schedule 1 methods.

The melody mutant line was derived from a recessive pedigree from the ENU mutagenesis screen at the MRC MGU Harwell. ENU-treated G0 C57BL/6 male mice were mated to $\mathrm{C} 3 \mathrm{H}$ female mice to produce $\mathrm{G} 1$ progeny. Female G1 mice were backcrossed to the ENU-treated G0 founder male to produce G3 mice which were screened for phenotypes caused by recessive mutations. The melody line was maintained on a $\mathrm{C} 3 \mathrm{H}$ genetic background by outcrossing and intercrossing successive generations. Caspase-3 null mice (B6.129S1-Casp $3^{\text {tmlFlv } / \mathrm{J})}$ were imported from The Jackson Laboratory (Bar Harbor, ME, USA) and rederived by in vitro fertilisation by the FESA core in the Mary Lyon Centre to maintain SPF status. The null mice were continually backcrossed to $\mathrm{C} 3 \mathrm{H}$.

\section{Clickbox}

Mice were placed in the palm of the hand and tested with a clickbox (Institute of Hearing Research, Nottingham, UK), which produces a brief audio stimulus of $\sim 20-\mathrm{kHz}$ tone at
$90 \mathrm{~dB}$ when held $30 \mathrm{~cm}$ away from the subject. Mice with unaffected hearing display the "preyer" response, a backwards flick of the ear pinnae. In most cases the preyer reflex is followed by a startled response that can range from a contracting of the neck muscles to a rapid jump backwards. A lack of either of the responses was recorded as no response to the clickbox (Hardisty-Hughes et al. 2010).

Auditory-evoked brainstem response analysis (ABR) (see Hardisty-Hughes et al. 2010)

Mice were anaesthetised with ketamine $\left(\right.$ Ketaset $\left.^{\mathrm{TM}}\right)$ and medetomidine (Domitor $\left.{ }^{\mathrm{TM}}\right)(0.5 \mathrm{ml}$ Domitor at $100 \mathrm{mg} / \mathrm{ml}$ with $4.12 \mathrm{ml}$ water and $0.38 \mathrm{ml}$ Ketaset at $1 \mathrm{mg} / \mathrm{ml}$; administered at a rate of $0.1 \mathrm{ml} / 10 \mathrm{~g}$ body weight). Animals were placed on a heated mat in an audiometric chamber (IAC 401-A-SE). Electrodes (Grass Telefactor F-E2-12) were placed subdermally over the vertex (active), right mastoid (reference), and left mastoid (ground). ABR responses were collected, amplified and averaged using TDT system III hardware and software (Tucker Davis Technology, Alachua, FL, USA). Click stimuli consisted of a $0.1-\mathrm{ms}$ broadband click of alternating polarity. Toneburst stimuli totalled 7-ms duration, including 1-ms rise/ fall time; frequencies used were $8,12,20$, and $26 \mathrm{kHz}$.

\section{Genetic mapping}

Extraction of DNA from mouse ear biopsies and PCR were performed using standard protocols. Single nucleotide polymorphism (SNP) markers, polymorphic between the parent $\mathrm{C} 57 \mathrm{BL} / 6$ and $\mathrm{C} 3 \mathrm{H}$ strains, were selected using the Mouse Phenome Database (MPD) (http://phenome.jax.org/ pub-cgi/phenome/mpdcgi?rtn=snps/door). An initial genome scan using DNA from affected G3 mice was performed using a panel of SNP markers by pyrosequencing on a PSQ HS 96A pyrosequencer (Biotage AB). After linkage was found, fine mapping was performed by selecting further SNP markers to narrow the nonrecombinant region.

\section{Candidate gene selection and mutation detection}

A list of genes that map to the nonrecombinant region identified in the genome scan was obtained using the Ensembl database (http://www.ensembl.org/Mus_musculus/ Info/Index). Candidates were selected by searching the Mouse Genome Informatics (MGI) database (http://www. informatics.jax.org/searches/allele_form.shtml) for genes known to be connected with hearing loss. Primers were designed around the exons of candidate genes, and DNA from melody homozygote, heterozygote, and both parental strains was PCR amplified and sent for genetic sequencing (Geneservice, Oxford, UK). For mutation detection the resulting 
sequence was analysed using DNAbaser v2 (Cubic Design) software.

\section{Genotyping}

The melody $\left(\right.$ Casp $\left.3^{\text {mldy }}\right)$ mutation introduced a SmaI restriction site. This enabled a genotyping assay to be performed by PCR amplification of exon 6 of Casp3 with the primers $5^{\prime}$-CTT CCT AGT TCT CAG ACC ACA CTT$3^{\prime}$ and $5^{\prime}$-CAT TTT CTC ACC AGG TGC TGT-3', yielding a product of $225 \mathrm{bp}$. Upon digestion with SmaI, only the 225-bp band is visible in $+/+$ genomic DNA, two bands of 100 and $125 \mathrm{bp}$ can be seen in Casp $3^{\text {mldy }}$ / Casp $3^{\text {mldy }}$, and all three bands are present in Casp $3^{\text {mldy }} /+$. Casp $3^{\text {tmlFlv }}$ mice were genotyped by PCR amplification in accordance with the protocol outlined on The Jackson Laboratory website (http://jaxmice.jax.org/protocolsdb/ $\mathrm{f}$ ? $=116: 2: 954450999895056:$ NO:2:P2_MASTER_PROT OCOL_ID,P2_JRS_CODE:3892,006233).

Histological analysis (see Hardisty-Hughes et al. 2010)

Animals were euthanized by cervical dislocation. The heads were removed, skinned, and bisected down the midline before fixation by submersion in $10 \%$ neutral buffered formaldehyde. Fixed specimens were decalcified and embedded in paraffin. Five-micrometre-thick sagittal sections were obtained and stained with $\mathrm{H} \& \mathrm{E}$ according to standard protocols. For spiral ganglion neuron density measurements, slides were digitally scanned using a Hamamatsu NanoZoomer slide scanner and the area containing the spiral ganglion neurons (Rosenthal's canal) was calculated using NDP serve software. Spiral ganglion neurons were counted (no distinction was made between Type I and II cells) and normalised to the calculated area. A Levene test of homogeneity of variances was performed and subsequent statistical analysis was performed using an ANOVA. As a result of the Levene test, Tamhane post hoc analysis was used for the mid and basal turns, and Tukey HSD post hoc analysis was used for the apical turn in SPSS software (SPSS, Inc., Chicago, IL).

Scanning electron microscopy (see Hardisty-Hughes et al. 2010)

Animals were euthanized and heads skinned and bisected as previously described. Inner ears were dissected and fixed in $2.5 \%$ glutaraldehyde in a 0.1 potassium phosphate buffer solution for 3-4 h before decalcification by submersion in $4.3 \%$ EDTA for $48 \mathrm{~h}$. Fine dissection was performed to remove the cochlear shell and stria-vascularis before osmium tetroxide-thiocarbohydrazide (OTOTO) processing (adapted from Hunter-Duvar 1978) was utilised to preserve stereocilia structure. Specimens were then dehydrated by submersion in ethanol solutions of increasing strength and stored in acetone until critical-point drying was performed using Emitech K850 (EM Technologies Ltd, Ashford, Kent, UK). Sputter coating was achieved using a Polaron instruments Inc. E5100. The specimens were examined with a Hitachi S-530 scanning electron microscope.

Protein extraction and fractionation

Protein was extracted using CelLytic NuCLEAR Extraction kit (Sigma-Aldrich, NXTRACT-1KT 078K4112). E17.5 heads were lysed in $1 \times$ lysis buffer containing protease inhibitors using a glass homogenizer. Nuclei were pelleted by centrifugation, and the cytoplasmic fraction contained in the supernatant was separated. Ten micrograms of each cytoplasmic protein sample were run on a $12 \%$ Bis-Tris minigel (Invitrogen, NP0341BOX); the nuclear fraction was discarded.

\section{Western blotting}

Protein was transferred onto a nitrocellulose membrane (Invitrogen LC2000) and blocked in TBS containing 5\% dry skimmed milk and $0.1 \%$ Tween 20 . The membrane was incubated with a Caspase-3 antibody (Cell Signalling \#9662) at 1:500 dilution in blocking solution overnight at $4^{\circ} \mathrm{C}$. Secondary anti-rabbit HRP-conjugated antibody (Sigma Aldrich A4914) was used at 1:10,000 dilution in blocking solution for $1 \mathrm{~h}$ at room temperature. Membranes were washed four times after both primary and secondary antibody incubations in TBS $+0.1 \%$ Tween 20. Enhanced chemiluminescence (GE Healthcare, RPN2109) was used as the detection system. An $\alpha$-tubulin antibody (Abcam, ab15246) at 1:500 dilution was used as described above as a loading control.

\section{Results}

Identification of the melody mutant

The melody (mldy) mutant was identified from a recessive ENU sensory screen undertaken at the MRC Mammalian Genetics Unit, Harwell (see "Materials and methods"). The founder G3 mice carrying the melody mutation appeared slightly smaller than littermates and had no response to a clickbox. Some mutants were observed to have cranial protuberances (Fig. 1).

Genetic mapping and candidate gene selection

An initial genome scan using a total of 13 progeny [both G3 progeny $(n=2)$ and G5 progeny $(n=11)]$ showed 

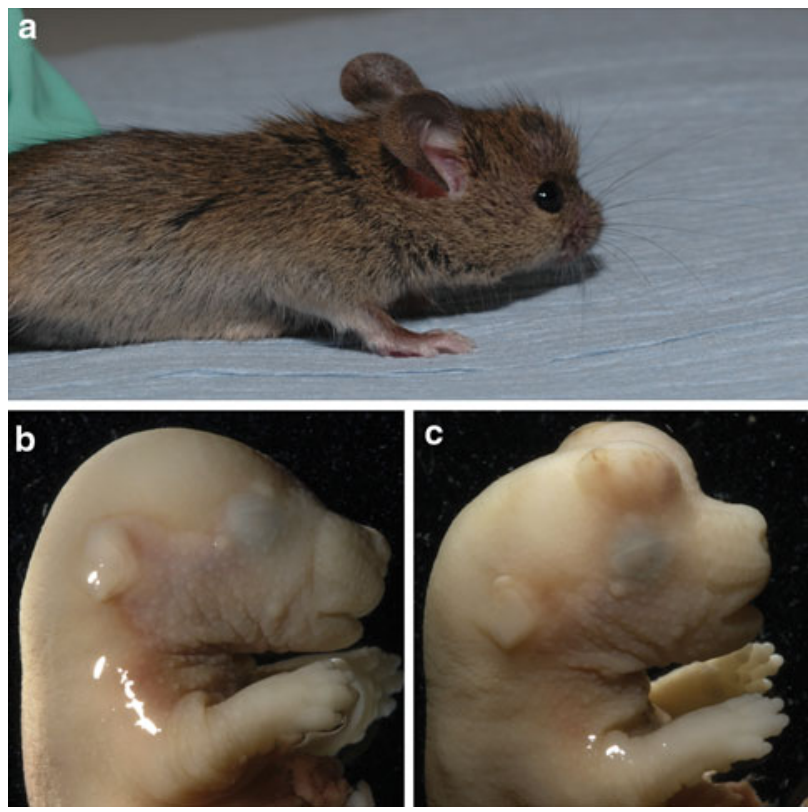

Fig. 1 a An example of an abnormal growth on the head of a mldy/ mldy mouse, probably due to hyperplasia of various cells in the brain. b, c A comparison of $+/+$ (b) and mldy/mldy (c) mice with abnormal protrusions from the brain at E17.5. This phenotype was seen in 50\% of mldy/mldy embryos examined and probably results in embryonic lethality in most cases, leading to the lower than expected numbers of mldy/mldy born (11.4\%)

linkage to chromosome 8. Subsequent fine mapping of 57 affected mice (from subsequent generations to G11) with SNP markers narrowed the mutant locus to approximately
$6 \mathrm{Mb}$ between the markers rs32804682 and rs37373014, a region containing approximately 60 genes. In this region there were a number of candidate genes that had known mutations demonstrating a hearing loss phenotype. Caspase 3 represented a good candidate as mice lacking Caspase 3 were reported to have similar phenotypic traits to those observed in mldy/mldy mice (Kuida et al. 1996; Morishita et al. 2001; Takahashi et al. 2001).

DNA from mldy/mldy and mldy/+ mice was PCR amplified using primers for each of the six exons of Casp3 and the sequence examined for mutations. The sequence contained a G-to-C transversion of nucleotide 489 of Casp3 located in exon 6 (Fig. 2a), causing a nonconservative cysteine-to-serine change at amino acid 163 . The residue changed by the melody mutation is the catalytic cysteine of murine Caspase 3 and is highly conserved through evolution (Fig. 2b). Not only is this catalytic cysteine conserved in Caspase 3, it is central in the pentapeptide active site motif QACXG ( $\mathrm{X}$ being $\mathrm{R}, \mathrm{G}$, or $\mathrm{Q}$ ) conserved in all caspases (Cohen 1997) (Fig. 2c).

\section{Complementation testing and phenotyping}

We undertook to confirm our identification of the melody (Casp $3^{\text {mldy }}$ ) mutation by complementation testing with the Caspase-3-null mutant Casp $3^{\text {tmlFlv }}$. Moreover, in parallel we carried out an extensive and detailed auditory and phenotypic analysis of both melody and null mutations as well as compound genotypes.

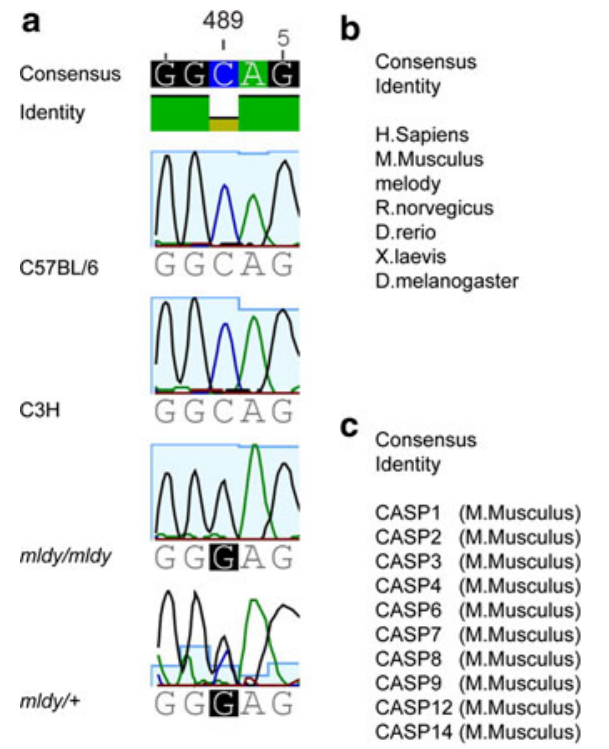

Fig. 2 A Caspase-3 mutation in the melody mutant. a Sequence at and around nucleotide 489 (highlighted by red ovals) of the exonic sequence of Casp3. The sequence shows cytosine at nucleotide 489 in the C57BL/ $6 \mathrm{~J}$ and $\mathrm{C} 3 \mathrm{H}$ parental strains and guanine at the same point in the Casp $3^{\text {mldy }} /$ Casp $^{\text {mldy }}$ sequence. The Casp $3^{\text {mldy }} /+$ sequence shows both cytosine and guanine. Note that the reverse complement sequence is

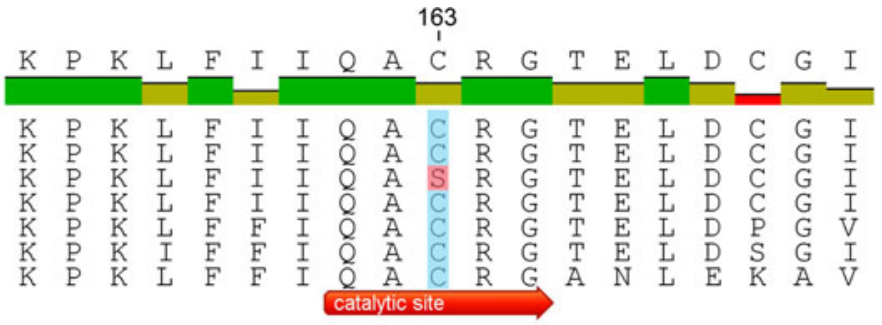

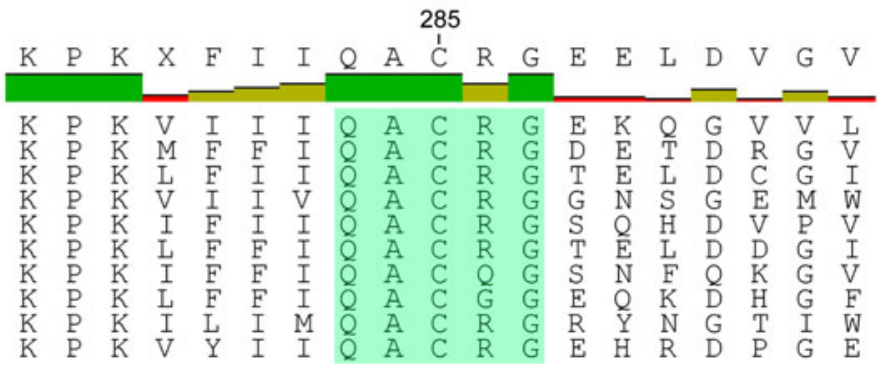

shown; therefore, the melody mutation is G489C. b Evolutionary conservation of the catalytic cysteine residue of Caspase 3 altered to serine in the melody mutant (black box). c Conservation of the QACXG pentapeptide active site motif (black box), which is present in all caspases. An alignment of peptide sequences from all the murine caspases is shown; the residue number refers to Caspase 1 


\section{Clickbox phenotyping}

We generated 537 intercross offspring from Casp $^{\text {mldy }}$ / + matings and assessed them for auditory function with a clickbox at four weeks of age. Of these, 61 mice (11.4\%) were deaf by clickbox as they did not exhibit the preyer reflex or any form of startle response. All of these mice were genotyped as $\operatorname{Casp} 3^{\text {mldy }} / \operatorname{Casp}^{\text {mldy }}$. In contrast, all Casp $3^{\text {mldy }} /+$ and $+/+$ mice showed a preyer reflex in response to the clickbox.

We generated 68 offspring from matings of Casp $3^{\text {mldy }}$ / Casp $3^{\text {mldy }}$ mice to Casp $3^{\text {tmlFlv }} /+$ mutants. From these progeny, 23 (33.8\%), all of which genotyped as Casp $3^{\text {mldy }}$ / Casp $3^{\text {tmlFlv }}$, showed no response to the clickbox at four weeks of age, indicating noncomplementation and confirming that a mutation in Caspase 3 is the cause of deafness in melody mutants. We also generated 159 progeny from $\operatorname{Casp}^{\text {tmlFlv }} /+$ intercross matings. From these, 18 (11.3\%) were genotyped as $C a s p 3^{t m 1 F l v} / \operatorname{Casp}^{\text {tmlFlv }}$, none of which showed a response to the clickbox at four weeks of age. In contrast, all $\operatorname{Casp}^{t m 1 F l v} /+$ and $+/+$ mice showed the preyer response to the clickbox.

\section{Embryonic phenotyping}

The number of $C a s p 3^{\text {mldy }} /$ Casp $3^{\text {mldy }}$ mice born is significantly lower than the $25 \%$ that would be expected according to Mendelian inheritance from a recessive mating scheme $\left(\chi^{2} P=3 \times 10^{-13}\right)$. To investigate this further, we opened up females from two intercrosses, one Casp $3^{\text {mldy }} /+\times$ Casp $3^{\text {mldy }} /+$ and one Casp $3^{\text {mldy }} /$ Casp $3^{\text {mldy }}$ $\times$ Casp $3^{m l d y} /+$, and harvested 19 embryos at $17.5 \mathrm{dpc}$. Of these, six were genotyped as $C a s p 3^{\text {mldy }} / \mathrm{Casp}^{\text {mldy }}$ and 50\% of these displayed severe blebs on their head (Fig. 1c), possibly due to hyperplasia of the brain, which may have led to prenatal losses.

\section{ABR analysis}

We analysed both melody and Casp3-null mice by ABR to establish in detail the nature of the hearing impairment. Twelve-week-old $C a s p 3^{\text {mldy }} / \operatorname{Casp}^{\text {mldy }}$ mice $(n=5)$ were subjected to tone-burst ABR assessment. None of the Casp $3^{\text {mldy }} /$ Casp $^{\text {mldy }}$ mice showed an ABR response at any of the test frequencies, $8,12,20$, and $26 \mathrm{kHz}$, at the maximum level tested, $90 \mathrm{~dB}$ SPL (for graphical representation, this was recorded as a threshold of $100 \mathrm{~dB}$ SPL). In contrast, $+/+$ mice all showed threshold levels typical for wild-type mice of the same age (Fig. 3a, b). Because no $\mathrm{ABR}$ response was seen at any frequencies using tone bursts, it was deemed that further ABR assessment using a click stimulus would be sufficient to characterise the deafness phenotype.
To confirm the lack of a heterozygous deafness phenotype, an outcross litter arising from a $\operatorname{Casp} 3^{\text {mldy }} / \operatorname{Casp}^{\text {mldy }}$ to $\mathrm{C} 3 \mathrm{H}$ mating was tested at 14 weeks of age. These mice (all $\mathrm{Casp}^{\text {mldy }} /+$ ) had click ABR thresholds between 20 and $25 \mathrm{~dB}$ SPL (data not shown). An additional 23 animals between 4 and 8 weeks of age and arising from melody intercross matings were tested by click ABR. There were four $C a s p 3^{\text {mldy }} /$ Casp $^{\text {mldy }}$ mice in this group, all of which failed to show response to the click ABR stimulus at the maximum level tested $(90 \mathrm{~dB}$ SPL). All $+/+$ and Casp $3^{m l d y} /+$ mice had click ABR thresholds ranging from 15 to $30 \mathrm{~dB}$ SPL (Fig. 3c).

A total of 27 progeny from $\operatorname{Casp}^{\text {tmlFlv }} /+$ intercross matings underwent click ABR testing at 8 weeks of age (Fig. 3c). From these, four genotyped as Casp3 $3^{\text {tmlFlv }}$ / $\operatorname{Casp}^{\text {tmlFlv }}$ and showed no response to the click stimulus at $90 \mathrm{~dB}$ SPL. All Casp $3^{\text {tm } 1 F l v} /+$ and $+/+$ mice had ABR thresholds between 20 and $25 \mathrm{~dB}$ SPL. As expected, click ABR performed on 8-week-old offspring from the complementation matings demonstrated that Casp $3^{\text {mldy }} /$ Casp $3^{t m 1 F l v}$ mice $(n=11)$ failed to elicit any response to the $90 \mathrm{~dB}$ SPL click stimulus. A summary of the click ABR data can be seen in Fig. 3c.

We also carried out ABRs to determine if there was evidence of hearing loss at earlier time points and analysed a small number of mice for each genotype at two weeks. These included two Casp $3^{\text {mldy }} /$ Casp $3^{\text {mldy }}$ and two Casp $3^{\text {tmlFlv }} / \mathrm{Casp}^{\text {tml }}{ }^{\mathrm{Flv}}$ mice, all of which failed to show a response to a 90-dB-SPL click ABR stimulus. Four Casp $3^{m l d y} / \mathrm{Casp}^{\text {tmI IFlv }^{2}}$ mice were also tested: three failed to show a response to the highest-level click stimulus and one had a click ABR threshold of $75 \mathrm{~dB}$ SPL. All $+/+(n=7)$ and heterozygote mice [Casp $3^{t m 1 F l v} /+(n=11), \operatorname{Casp}^{m l d y}$ ] $+(n=4)]$ had ABR thresholds between 20 and $35 \mathrm{~dB}$ SPL, with the exception of one $\operatorname{Casp}^{\text {tmlFlv }} /+$ mouse which had a threshold of $50 \mathrm{~dB}$ SPL. This mouse was very small compared to littermates and it is possible this elevated threshold was due to either ill health or difficulties with electrode placement because of the very small size of the animal. These data show that by two weeks of age, shortly after the onset of hearing in mice, Casp $3^{\text {mldy }} / \operatorname{Casp}^{\text {mldy }}$, $\operatorname{Casp}^{\text {tmlFlv }} / \mathrm{Casp}^{\text {tmlFlv }}$, and Casp $3^{\text {mldy }} / \operatorname{Casp}^{\text {tmlFlv }}$ already display severe hearing loss.

\section{Western blot analysis}

We analysed protein levels in both melody and Casp3-null mutants as well as in compound genotypes. Caspase 3 is located mainly in the cytoplasm in its uncleaved form. Therefore, we proceeded to fractionate the total protein into cytoplasmic and nuclear fractions. Cytoplasmic protein extracted from E17.5 heads from all genotypic variants 

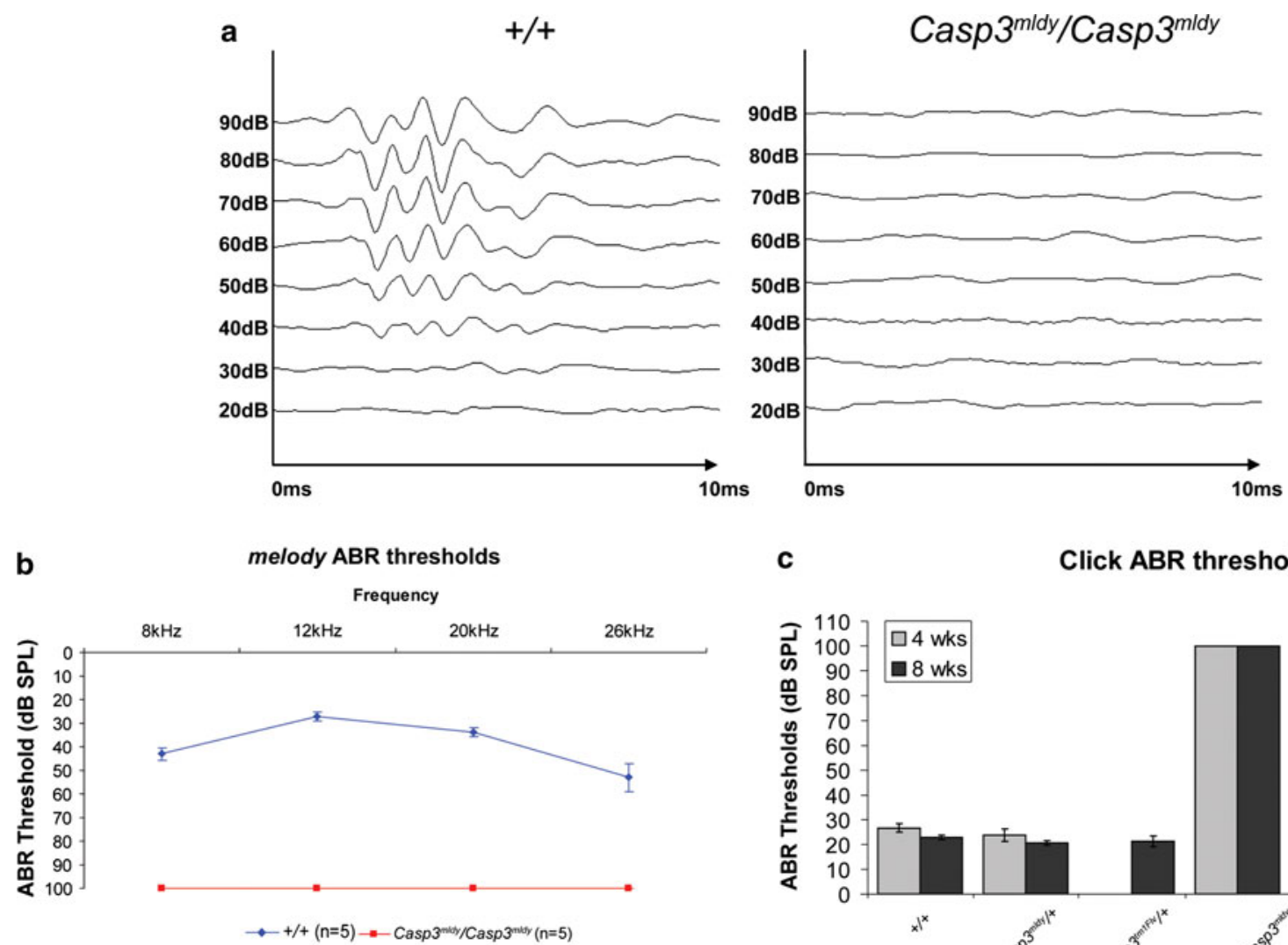

C

\section{Click ABR thresholds}

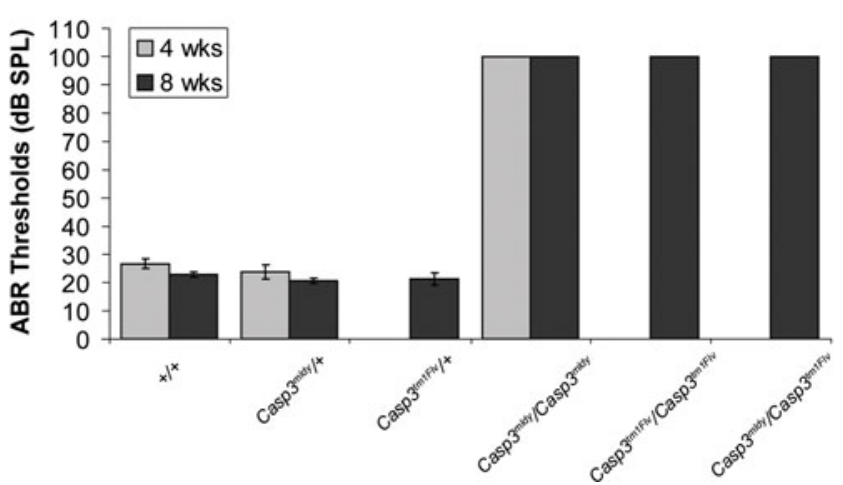

Fig. 3 ABR data from melody mutant mice. a Representative traces from 12-week-old $+/+$ and Casp $3^{\text {mldy }} /$ Casp $3^{\text {mldy }}$ mice in response to $12-\mathrm{kHz}$ tone-burst stimuli at decreasing stimuli levels. In the wildtype mice, the five main ABR peaks can be seen in response to the stimulus at levels down to $30 \mathrm{~dB}$ SPL. In the Casp $3^{\text {mldy }} /$ Casp $3^{\text {mldy }}$ mice, no peaks are observed at any of the stimulus levels. b Audiogram showing average ABR threshold levels for 12-weekold $+/+$ and Casp $3^{\text {mldy }} /$ Casp $3^{\text {mldy }}$ mice $(n=5)$. The error bars denote the standard error of the mean. Casp $3^{\text {mldy }} /$ Casp $^{\text {mldy }}$ mice showed no response to the highest stimulus level ( $90 \mathrm{~dB}$ SPL) at any of the test frequencies $(8,12,20$, and $26 \mathrm{kHz})$. For graphical representation, the $\operatorname{Casp}^{\text {mldy }} /$ Casp $^{\text {mldy }}$ thresholds are plotted as

was probed with a Caspase-3 antibody (Fig. 4). There was no significant difference in Caspase-3 levels between Casp $3^{\text {mldy }} /+$, $\mathrm{C} 3 \mathrm{H}$, and $+/+$ mice $(\mathrm{C} 3 \mathrm{H} / \mathrm{C} 57 \mathrm{BL} / 6 \mathrm{~J})$. Caspase-3 levels were significantly lower in Casp3 $3^{\text {mldy }}$ / Casp $3^{\text {mldy }}$ mice compared to controls, and although not significantly different than in controls, the levels in Casp $3^{\text {mldy }} /+$ mice were intermediate between wild-type and $C a s p 3^{m l d y} / C a s p 3^{m l d y}$ mice. Casp $3^{\text {tm } 1 F l v} /+$ levels were around half that seen in wild-type mice and levels in Casp $3^{m l d y} /$ Casp $^{\text {tmlFlv }}$ mice were further reduced. In addition, protein levels in $C a s p 3^{\text {tm } 1 F l v} /+$ and $C a s p 3^{\text {mldy }} /$ Casp $3^{\text {tmlFlv }}$ were significantly lower when compared with that in $C a s p 3^{m l d y} /+(P \leq 0.05)$. As expected, the level of Caspase 3 in the Casp $3^{\text {mldy }} /$ Casp $^{\text {tm1Flv }}$ was significantly lower than in $C a s p 3^{m l d y} / C a s p 3^{m l d y}$ mice $(P \leq 0.05)$.

$100 \mathrm{~dB}$ SPL. c Average ABR thresholds in response to a click stimulus of $+/+(n=10$, with three aged 4 weeks and seven aged 8 weeks $),$ Casp $^{\text {mldy }} /+(n=20$ with four aged 4 weeks and 16 aged 8 weeks), Casp $3^{\text {tmlFlv }} /+(n=12$ with all aged 8 weeks $), C a s p 3^{\text {mldy }}$, $\operatorname{Casp}^{\text {mldy }}$ ( $n=4$ with one aged 4 weeks and three aged 8 weeks), Casp $^{\text {tmlFlv }} /$ Casp $^{\text {tmlFlv }} \quad(n=4$ with all aged 8 weeks $)$ and Casp $^{\text {mldy }} /$ Casp $^{\text {tmlFlv }}$ ( $n=11$ with all aged 8 weeks). All $+/+$, Casp $3^{m l d y} /+$, and Casp $^{\text {tmlFlv }} /+$ mice had ABR thresholds between 15 and $30 \mathrm{~dB}$ SPL. No response to the highest stimulus level $(90 \mathrm{~dB}$ SPL) was seen in any of the Casp $3^{\text {mldy }} /$ Casp $^{\text {mldy }}$, Casp $3^{\text {tmlFlv }}$ / Casp $3^{\text {tmlFlv }}$, or Casp $3^{\text {mldy }} /$ Casp $^{\text {tmlFlv }}$. For graphical representation, thresholds are plotted as $100 \mathrm{~dB}$ SPL

Casp $3^{\text {tm1Flv }} / \mathrm{Casp}^{\text {tm1Flv }}$ animals were confirmed as null by the lack of any observable protein.

\section{Scanning electron microscopy}

Scanning electron micrographs (SEM) were obtained from Casp3 $3^{\text {mldy }} /$ Casp $^{\text {mldy }}$, Casp3 $^{\text {tm1Flv }} /$ Casp $^{\text {tm1Flv }}$, Casp3 $3^{\text {mldy }} /$ Casp3 $3^{\text {tm1Flv }}$, Casp $^{\text {tmlFlv }} /+$, Casp $3^{\text {mldy }} /+$, and $+/+$ mice between 2 and 3 months old. The images show that Casp3 $3^{\text {mldy }} /$ Casp $^{\text {mldy }}$ mice display severe abnormalities of both inner-hair-cell (IHC), and outer-hair-cell (OHC) stereocilia bundles (Fig. 5). The three organised rows of OHCs seen in the organ of Corti of $+/+$ mice are not observed in Casp3 $3^{\text {mldy }} /$ Casp $^{\text {mldy }}$ animals (Fig. 5ai-di). 


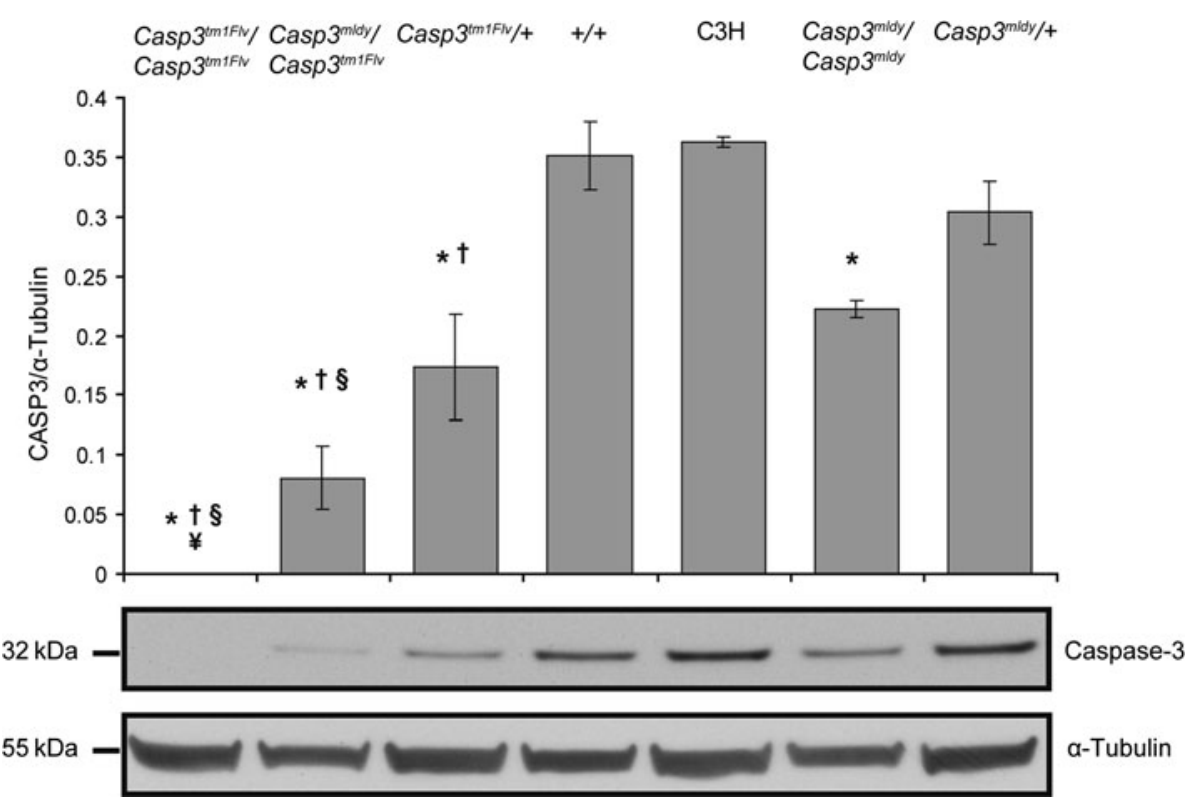

Fig. 4 Western blot analysis of cytoplasmic protein from E17.5 heads of Casp $3^{\text {tmlFlv }} /$ Casp $^{\text {tmIFlv }}$, Casp $^{\text {mldy }} /$ Casp $^{\text {tmlFlv }}$, Casp $3^{\text {tmlFlv }} /+,+/+, \mathrm{C} 3 \mathrm{H}$, Casp $^{\text {mldy }} /$ Casp $^{\text {mldy }}$, and Casp $3^{m l d y} /+$ mice $(n=3)$. a Average protein expression levels from each of the genotypes with the standard error of the mean. Protein levels are normalised with $\alpha$-tubulin as a loading control. An ANOVA was

Extensive abnormalities of OHCs in the organ of Corti are

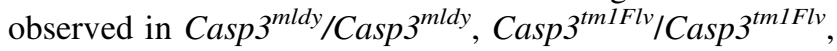
and $C a s p 3^{m l d y} / C a s p 3^{\text {tmlFlv }}$ when compared to wild-type mice, including stereocilia fusion and hair cell loss. The severity of hair cell degeneration varies along the cochlea, although there is no observable pattern between specimens. Some small areas of the organ of Corti are unaffected and show what appears to be normal OHC stereocilia morphology, and others totally lack OHC stereocilia. In addition to the widespread degeneration, some of the remaining $\mathrm{OHC}$ stereocilia appear to be fused at the tips, and separate bundles also appear connected (Fig. 5aiiidiii). Similar stereocilia abnormalities, including the connecting material between $\mathrm{OHC}$ bundles, were previously reported in the B6.129S1-Casp $3^{\text {tmlFlv } / \mathrm{J}}$-ull mice (Takahashi et al. 2001); however, we cannot rule out that this phenotype is due to an artefact. Extensive abnormalities are also seen for IHCs. Most of the IHC stereocilia have also fused together and are larger than normal size, although IHC degeneration is not as severe or widespread as that of the OHCs (Fig. 5aii-dii). These hair cell abnormalities are not seen in the $C a s p 3^{\text {mldy }} /+$ or Casp $3^{\text {tm1Flv }} /+$ mice (data not shown).

\section{Histology}

Histological examination of sagittal sections from the cochlea of 8-week-old mice show reduced numbers of performed using Tukey HSD post hoc analysis. Significant differences in protein levels are shown: * reduced compared to $\mathrm{C} 3 \mathrm{H}$ or $+/+(P \leq 0.05) ; \dagger$, reduced compared to $C a s p 3^{m l d y} /+(p \leq 0.05) ; \S$, reduced compared to $C a s p 3^{\text {mldy }} / \operatorname{Casp}^{\text {mldy }}(p \leq 0.05)$; and $¥$, reduced compared to $\operatorname{Casp}^{\text {tmlFlv }} /+(p \leq 0.05)$. b An example Western blot probed with the Caspase- 3 antibody and the $\alpha$-tubulin loading control

spiral ganglion (SG) neurons in Casp $3^{\text {mldy }} /$ Casp $3^{\text {mldy }}$, $\mathrm{Casp}^{\text {mldy }} / \mathrm{Casp} 3^{\text {tmlFlv }}$, and Casp $3^{\text {tmlFlv }} / \mathrm{Casp} 3^{\text {tmlFlv }}$ mice (Figs. 6 and 7a). We have determined SG neuron density in apical, mid, and basal turns of $+/+, \operatorname{Casp}^{\text {mldy }} /+$,

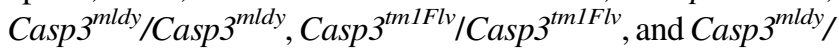
Casp $^{\text {tmlFlv }}$ mice (Fig. 7a, b). There were no significant differences in SG neuron density between $+/+$ and $\operatorname{Casp}^{3^{t m I F l v}} /$ + mice in any of the turns of the cochlea. Casp $3^{\text {mldy }} /+$ appeared to show reduced SG density compared with $+/+$ and $C a s p 3^{t m 1 F l v} /+$ mice in all turns of the cochlea, with significant differences seen when compared to Casp $3^{\text {tmlFlv }}$ / + in the apical and mid turns $(P<0.05)$. Casp $3^{\text {mldy }} /$ Casp $3^{\text {mldy }}$ and $C a s p 3^{m l d y} / C a s p 3^{t m l F l v}$ mice showed significantly reduced SG neuron density in all cochlear turns when compared to $+/+$ and Casp $^{\text {tmlFlv }} /+(P<0.05)$. Casp $3^{\text {mldy }} /$ Casp $3^{\text {mldy }}$ SG density was lower than that of $C a s p 3^{m l d y} /+$ in all turns but was only statistically significant in the basal turn $(P<0.05)$. Interestingly, the Casp $3^{\text {tmlFlv }} / C a s p 3^{t m 1 F l v}$ mice showed a reduction in density in the mid and basal turns compared to $+/+(P<0.05)$, but not in the apical turn where, in fact, SG density was significantly higher than in $C a s p 3^{m l d y} /+$ and Casp $3^{m l d y} / \operatorname{Casp}^{\text {mldy }}(P<0.05)$. Finally, the SG neuron density in $\mathrm{Casp}^{\mathrm{mld}} / \mathrm{Casp}^{3^{\mathrm{ml} I F l v}}$ mice was lower than in

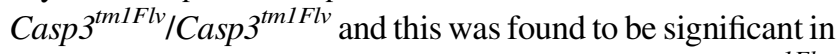
the apical turns, although it is here that $\operatorname{Casp}^{\text {tmlFlv }}$ Casp $3^{\text {tmlFlv }}$ mice have a higher SG neuron density.

Overall, there appeared to be an apex-to-base gradient of severity of effects on SG neuron density in the mutant 
Fig. 5 Scanning electron micrographs showing abnormal hair cell morphology in the cochlea of Casp $3^{\text {mldy }} / \mathrm{Casp}^{\text {mldy }}$ $(n=3)$, Casp $^{m l d y} /$ Casp $^{\text {tmlFlv }}$ $(n=2)$, Casp $^{\text {tmlFlv }}$, Casp $3^{\text {tmlFlv }}(n=2)$, and $+/+$ mice $(n=2)$ aged 2-3 months. Panel (a $i)$ shows a wild-type organ of Corti, and three well-organised rows of outer hair cells (OHC) and one row of inner hair cells (IHC) are visible. Casp $3^{\text {mldy }} /$ Casp $^{\text {mldy }}$ (bi), Casp3 $3^{\text {mldy } / C a s p 3^{\text {tmlFlv }}}$ (c i), and Casp $3^{\text {tmlFlv }}$ Casp $^{\text {tmlFlv }}(d$ i) display OHC degeneration and abnormalities of the stereocilia bundles of IHCs and OHCs. Panels (a ii)(d ii) show higher-magnification images of the IHCs, and panels (a iii)-(d iii) show highermagnification images of the OHCs. Casp $3^{\text {mldy }} /+(n=3)$ and Casp3 $3^{\text {tmlFlv }} /+(n=2)$ mice were also analysed (data not shown) but showed no differences to wild-type (see "Results")
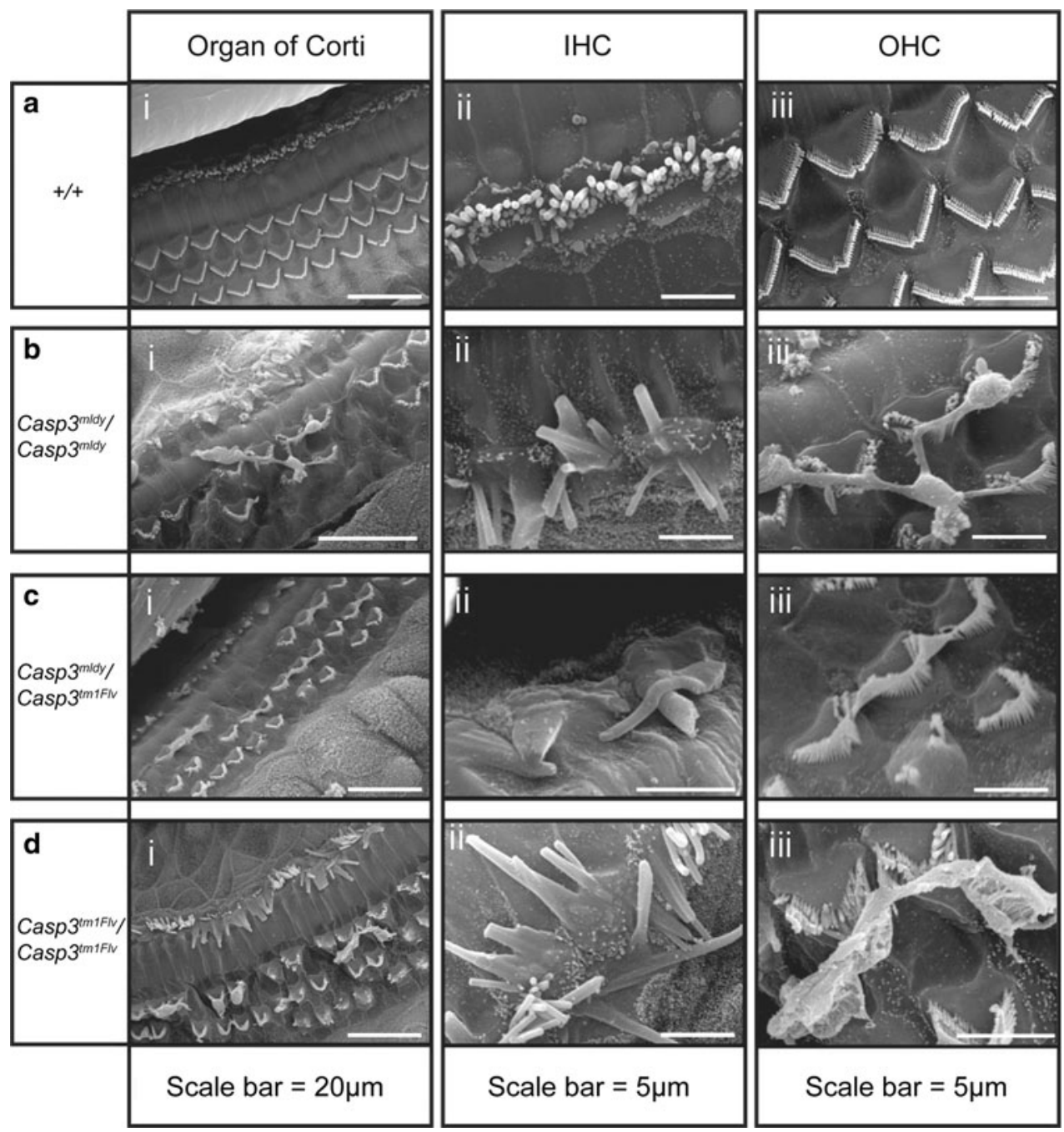

genotypes at 8 weeks of age. Density was shown to be significantly lower in both the basal and mid turns compared to apical turns in the Casp3 $3^{\text {tm1Flv }} / \operatorname{Casp}^{\text {tm1Flv }}$ and Casp $3^{m l d y} /$ Casp $^{\text {tmlFlv }}$ mice $(P<0.05)$; however, no differences were seen between the basal and mid turns. The same trend was seen in Casp $3^{\text {mldy }} / \operatorname{Casp}^{\text {mldy }}$, although there were no significant differences. We also analysed SG neuron density at an earlier time point, P18, and found that at this age there were no significant reductions in any of the genotypes (data not shown). Moreover, given our observations on the apex-to-base gradient of SG neuron density, we analysed the expression of Caspase 3 across the cochlea turn in wild-type, $C a s p 3^{\text {mldy }} /+$, and Casp $3^{\text {mldy }} / C a s p 3^{\text {mldy }}$ mice. We did not observe any apex-to-base gradient in Caspase-3 expression that might underlie the relative preservation of spiral ganglion cells in the apical regions (data not shown). We also analysed the expression of Caspase 7 for differences in expression across the cochlear turn that might contribute to the loss of SG neurons in the base, but again we did not observe any apex-to-base gradient (data not shown).

\section{Discussion}

We have identified a new mutation, melody, from an ENU recessive deafness screen, demonstrating a profound hearing loss. Melody carries a nonconservative mutation at the catalytic cysteine (amino acid 163) of Caspase 3. Caspase 3 is responsible either totally or in part for the cleavage of a large number of cytoskeletal proteins such as gelsolin, actin, and $\alpha$-fodrin, proteins involved with cell cycle and proliferation such as $\mathrm{Rb}$ and $\mathrm{p} 27^{\mathrm{kip} 1}$, and activating protein kinases such as MEKK1 (reviewed in Earnshaw et al. 1999). In a number of cases, Caspase 7, another executioner caspase that shares a high level of homology with Caspase 3, may take over the cleavage of substrates in its absence. For some substrates such as $\alpha$-fodrin, which is 
Fig. 6 Histological analysis of the spiral ganglion in the melody mutant. H\&E stained sections from the apical, mid, and basal turns of the cochlea from 2-month-old mice of each genotype are displayed. The degeneration in the apical turns is not as severe as the mid or basal turns. Scale bars $=100 \mu \mathrm{m}$

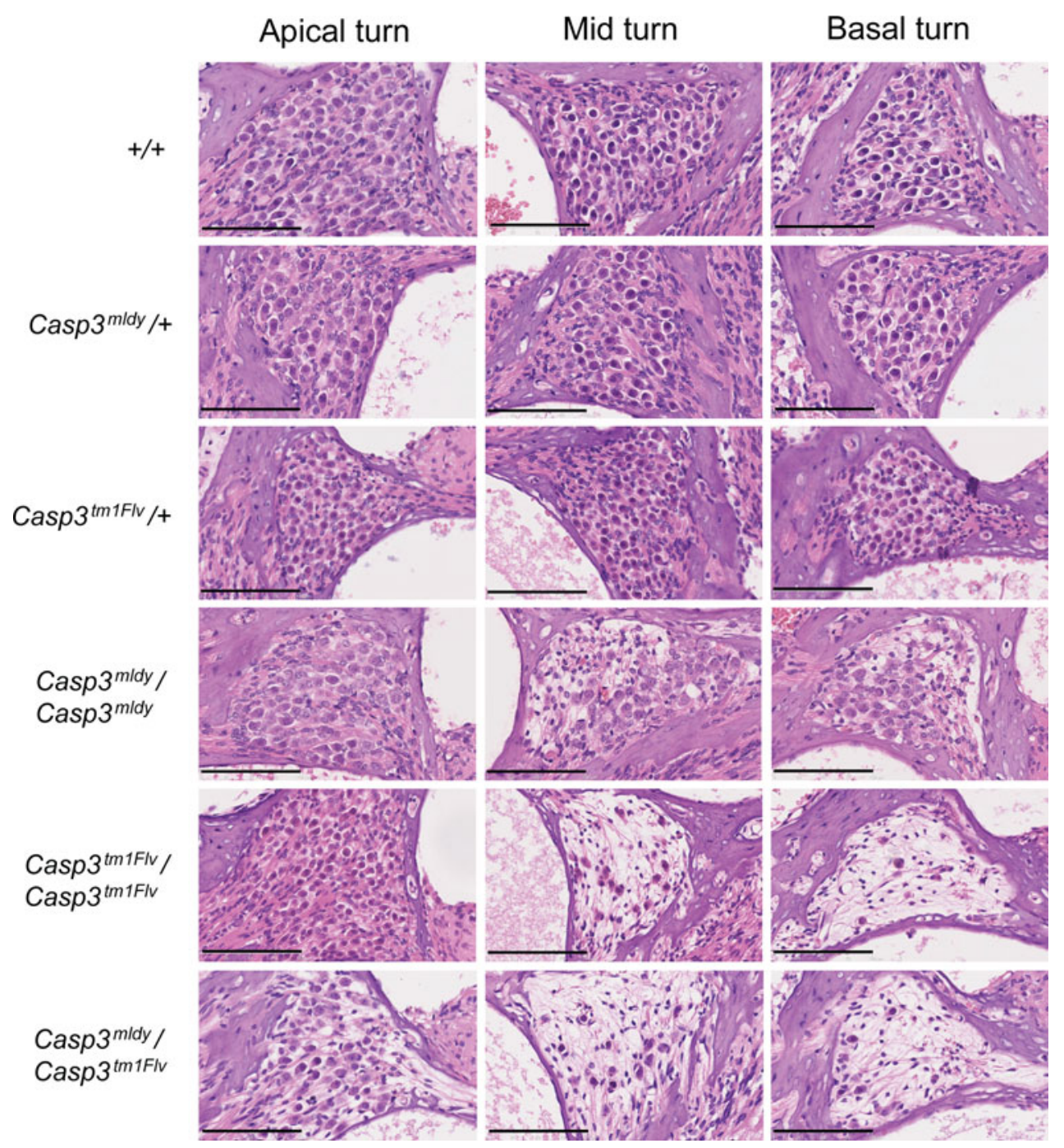

heavily involved with plasma membrane blebbing, Caspase 3 is indispensible for apoptotic cleavage (Janicke et al. 1998), although for neuronal apoptosis to occur it must be cleaved by both calpain and Caspase 3 at different sites (Nath et al. 1996). Calpain has long been associated with neuronal necrosis, and, interestingly, Caspase 3 has been shown to be involved with the cleavage of calpastatin, which in turn leads to reduced inhibition of calpain. Conversely, pro-Caspase 3 is a substrate of calpain, but instead of processing it into the active subunits, cleavage results in a truncation that reduces the chance of activation by initiator caspases (Wang 2000). It would be expected that the lack of a catalytically active Caspase 3 in melody or null homozygote mice leads to these pathways being compromised, resulting in a lack of the necessary developmental apoptosis in certain cell types in the organ of Corti and the brain. Most noteworthy for this study, Morishita et al. (2001) showed that Caspase 3 is expressed in spiral ganglion neurons during inner-ear development where it presumably plays some role in apoptosis.
The ENU melody mutation causes a similar phenotype to Casp3 -ull mice. However, there are some differences in severity. These differences may be due to the genetic background of the mice. Casp3 $3^{\text {tm } 1 F l v}$-null mice were originally created on a 129/sv genetic background and displayed severe brain hyperplasia and consequently died in utero or very shortly after birth (Kuida et al. 1996). The null mice used in this study were created by outcrossing heterozygous 129/sv null to C57BL/6 J for ten generations before intercrossing to produce the B6.129S1-Casp3 $3^{\text {tm 1Flv } / \mathrm{J}}$ mouse line. These mice were reported to have a much less severe phenotype than the $129 / \mathrm{sv}$ null; they displayed only minor brain abnormalities but developed sensorineural hearing loss due to degeneration of sensory cells (Takahashi et al. 2001). Mice homozygote for a different null allele, Casp3 ${ }^{\text {tm1Kin }}$, which were created and maintained on a C57BL/6 J background, also developed deafness due to degeneration of sensory hair cells and spiral ganglion (Morishita et al. 2001). Abnormally low ratios of homozygote null mice were not reported in these studies. 


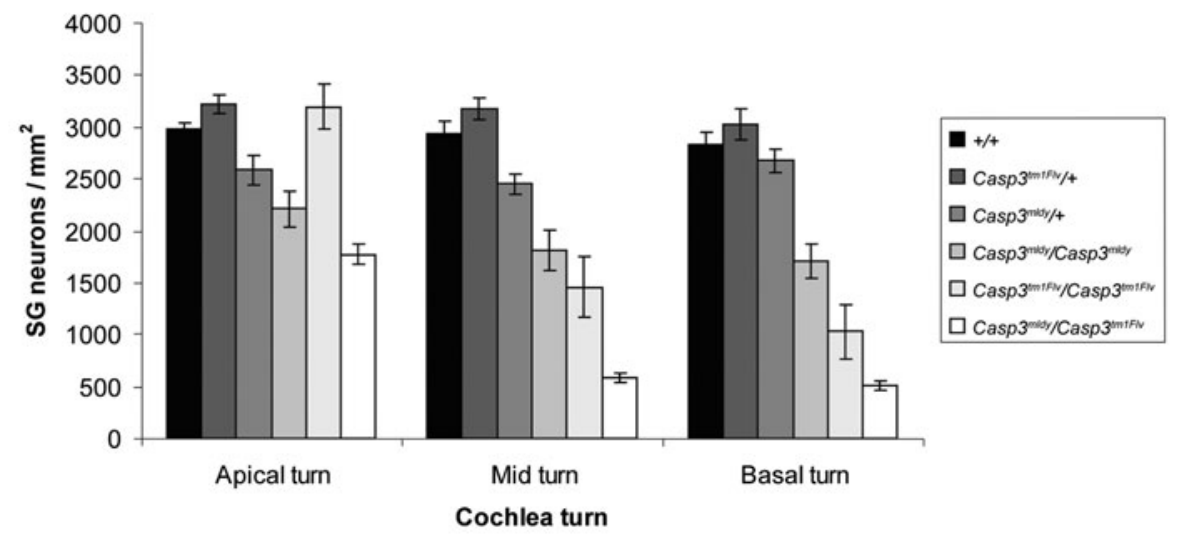

b

\begin{tabular}{|c|c|c|c|c|c|c|}
\hline Apical turn ( $p$ value) & $+/+$ & Casp $^{\text {tm1FN }} /+$ & 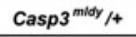 & 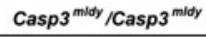 & Casp3 $3^{\text {tmiFN }} /$ Casp3 $^{\text {tmifN }}$ & Casp $^{\text {midy }} /$ Casp $^{\text {tmifin }}$ \\
\hline$+/+$ & - & & & & & \\
\hline $\operatorname{Casp}^{\operatorname{tm1FN} /+}$ & $>0.05$ & - & & & & \\
\hline Casp $3^{\text {mldy } /+}$ & $>0.05$ & 0.03613 & - & & & \\
\hline Casp $3^{\text {mldy }} /$ Casp $^{\text {midy }}$ & 0.00683 & 0.000246 & $>0.05$ & - & & \\
\hline Casp $^{\text {tm1FN }} /$ Casp $^{\text {tm1FN }}$ & $>0.05$ & $>0.05$ & 0.04939 & 0.00036 & - & \\
\hline Casp $3^{\text {midy }} /$ Casp $^{\text {tm1Flv }}$ & 0.00002 & 0.000001 & 0.00372 & $>0.05$ & 0.000001 & - \\
\hline Mid turn ( $\mathrm{p}$ value) & $+/+$ & Casp3 $^{\text {tm1FN } /+}$ & Casp $3^{\text {mlay } /+}$ & Casp $3^{\text {mldy }} /$ Casp $3^{\text {midy }}$ & Casp $3^{\text {tmiFN }} /$ Casp3 $^{\text {tmifN }}$ & Casp $3^{\text {mady }} /$ Casp $^{\text {tmifin }}$ \\
\hline$+/+$ & - & & & & & \\
\hline $\operatorname{Casp}^{\text {tmiFN } /+}$ & $>0.05$ & $\cdot$ & & & & \\
\hline Casp $3^{\text {mldy } /+}$ & $>0.05$ & 0.00960 & - & & & \\
\hline Casp $^{\text {midy }} /$ Casp $^{\text {midy }}$ & 0.01629 & 0.00454 & $>0.05$ & - & & \\
\hline $\operatorname{Casp}^{\text {tm1FN }} / \operatorname{Casp}^{\text {tm1FN }}$ & 0.03774 & 0.01753 & $>0.05$ & $>0.05$ & - & \\
\hline Casp $3^{\text {midy }} /$ Casp $^{\text {tm1Fl }}$ & 0.00003 & 0.00001 & 0.00001 & 0.018 & $>0.05$ & - \\
\hline Basal turn ( $p$ value) & $+/+$ & Casp $^{\text {tm1FN } /+}$ & Casp $3^{\text {midy } /+}$ & Casp $3^{\text {mldy }} /$ Casp $3^{\text {midy }}$ & Casp $3^{\text {tm1FN }} /$ Casp3 $^{\text {tm1FN }}$ & Casp $^{\text {midy }} /$ Casp $^{\text {tmifN }}$ \\
\hline$+/+$ & - & & & & & \\
\hline $\operatorname{Casp}^{\operatorname{tm} 1 F N} /+$ & $>0.05$ & - & & & & \\
\hline Casp $3^{\text {mldy } /+}$ & $>0.05$ & $>0.05$ & - & & & \\
\hline Casp $3^{\text {midy }} /$ Casp $^{\text {midy }}$ & 0.00611 & 0.00230 & 0.01472 & - & & \\
\hline Casp3 $3^{\text {tm1FN }} /$ Casp $^{\text {tm1FN }}$ & 0.00592 & 0.00257 & 0.01163 & $>0.05$ & - & \\
\hline Casp $3^{\text {midy }} /$ Casp $^{\text {tm1Fl }}$ & 0.00003 & 0.00006 & 0.00001 & 0.008 & $>0.05$ & - \\
\hline
\end{tabular}

Fig. 7 Analysis of spiral ganglion neuron densities between genotypes and between cochlear turns. a Spiral ganglion neuron densities for each genotype in the apical, mid, and basal turns of the cochlea are presented. The number of spiral ganglion neurons were counted and normalised to the area of Rosenthal's canal in each section to provide the spiral ganglion neuron density in $\mathrm{mm}^{2}$. Error bars denote standard

However, we maintained our null mice by outcrossing to $\mathrm{C} 3 \mathrm{H}$ and intercrossing progeny to produce Casp $3^{\text {tmlFlv }}$ / Casp3 $3^{\text {tmlFlv }}$ animals. The number of Casp3 $3^{\text {tmlFlv/ }}$ Casp3 $3^{\text {tmlFlv }}$ animals surviving (18 of $\left.159,11.4 \%\right)$ was significantly lower than the $25 \%$ expected according to Mendelian inheritance from a recessive mating scheme $\left(\chi^{2}\right.$ $P=0.00007)$. As already shown, the percentage of Casp $3^{\text {mldy }} /$ Casp $^{\text {mldy }}$ mice, also maintained on $\mathrm{C} 3 \mathrm{H}$, was very similar $(11.3 \%)$, and we demonstrated for melody that $50 \%$ of 17.5 -dpc homozygous embryos displayed severe error of the mean. Six sections from each genotype were analysed. b Table of statistically significant differences in spiral ganglion neuron density in the apical, mid, and basal turns. An ANOVA was performed using either Tukey HSD or Tamhane post hoc analysis (see "Materials and methods")

blebbing of the head, potentially contributing to prenatal losses. It would appear that both mutations display embryonic lethality on a $\mathrm{C} 3 \mathrm{H}$ background.

The lack of an ABR response reflecting a profound hearing loss in $C a s p 3^{\text {mldy }} /$ Casp $^{\text {mldy }}$ mice was already apparent by 2 weeks of age. It was previously reported that 2-week-old Casp3 $3^{\text {tm1Flv }} / \mathrm{Casp}^{\text {tm1Flv }}$ mice showed an atypical ABR response to a $70-\mathrm{dB}-\mathrm{SPL}$ stimulus but showed no response to a $100-\mathrm{dB}-\mathrm{SPL}$ stimulus by five weeks (Takahashi et al. 2001). It is also documented that 
some of the Casp $^{\text {tml Kin }}{ }^{\text {Casp }} 3^{\text {tmlKin }}$ mice showed very elevated but not absent ABR responses at four months of age (Morishita et al. 2001). Both Casp3 knockouts were analysed on a C57BL/6 background, a strain that shows age-related hearing loss. Overall, the melody homozygotes exhibited a hearing loss as profound as the knockout mutations, particularly when taking into account that melody was analysed on a $\mathrm{C} 3 \mathrm{H}$ hearing-sensitive background.

Degeneration and fusion of OHCs was reported in the previous study of the $\operatorname{Casp}^{\text {tmlFlv }}$ mutant (Takahashi et al. 2001). Moreover, Takahashi et al. reported some fusion of IHC stereocilia, although this was not particularly extensive and the bulk of IHC stereocilia appeared normal. Interestingly, the fusion of IHC that we observed in the Casp $3^{\text {tmlFlv }} / \mathrm{Casp}^{\text {tmlFlv }}$ mice appears much more extensive, affecting the bulk of inner-ear stereocilia. Takahashi et al. (2001) also reported increased numbers of border cells and persistence of the greater epithelial ridge, from which border cells and inner hair cells develop in the organ of Corti.

In the melody mutation we focused on its effects on degeneration of spiral ganglion neurons and carried out a detailed analysis of neuronal density in all genotypes across the cochlear turns. Morishita et al. (2001) reported degeneration of the spiral ganglion in the Caspase-3 knockout beginning at 30 days but did not quantify the effect or investigate its distribution across the cochlear turns. We have demonstrated that both homozygous mutants and the compound mutant show extensive hypocellularity of spiral ganglion neurons in Rosenthal's canal at eight weeks of age. We made two important observations. First, there is evidence of a gradient of severity in $\operatorname{Casp}^{\text {mldy }} / \mathrm{Casp}^{\text {mldy }}$, Casp $3^{\text {tmlFlv }} / \operatorname{Casp}^{\text {tmlFlv }}$, and the compound mutant, with the apical turns being severely affected the least. As a consequence of this observation, for both Caspase 3 and Caspase 7 we examined whether there was any evidence of apex-to-base gradients of expression in the cochlea but found none. Second, we noted that melody heterozygotes appeared to show some evidence of reductions in neuronal density in the spiral ganglion. Although they did not display the extent of hypocellularity that was seen in the melody homozygotes, null homozygotes, or compound mutants, the population of spiral ganglion neurons was significantly lower in apical and mid turns compared to that in heterozygous knockout mice $\left(\operatorname{Casp}^{t m l F l v} /+\right)$. Interestingly, there is also some evidence to suggest that effect on neuronal density is more severe in the compound mutant $\left(\mathrm{Casp}^{\mathrm{mldy}} / \mathrm{Casp}^{\text {tmlFlv }}\right)$ compared to that in the homozygous knockout, which would be consistent with the melody mutation exerting a dominant negative effect. Overall, our evidence indicates that the melody mutation may show some dominant effects in the spiral ganglion, although we have seen no dominant effects from ABR measurements where auditory thresholds correspond to wild type in the heterozygote. It is notable that we found some reduction in protein levels in the melody heterozygote (see "Results"), though this was not significant. The reduced SG neuron density in melody heterozygotes is also noteworthy given that heterozygotes show no hair cell abnormalities or loss. The absence of any degeneration of SG neurons at P18 for any genotype might suggest that SG neuron loss is secondary to hair cell loss. However, our observations in melody heterozygotes would indicate that the Caspase- 3 mutant acts directly on the spiral ganglion cells and not as a secondary consequence of hair cell loss.

It is not inconceivable, given the nature of the melody mutation, that mutant protein may bind, but not degrade, and thus sequester substrates leading to dominant effects in the heterozygote in some tissues. Indeed, the exact substitution caused by the melody mutation has been created by targeted mutagenesis and is often used as a catalytically inactive form of Caspase 3 for the study of caspase activity in in vitro experiments (Bose and Clark 2005; Feeney and Clark 2005; Gu et al. 1995; Kang et al. 2008; Van Criekinge et al. 1996). This catalytically inactive form has been shown to fold into the active form and bind to substrates of Caspase 3 but it is unable to cleave them due to the mutated active site (Dejosez et al. 2008).

In conclusion, we have identified a new Caspase-3 mutation, leading to the alteration of the catalytically active cysteine, and explored its effect on auditory function and the spiral ganglion in the inner ear. We have demonstrated a gradient of effect in the spiral ganglion across the cochlea turns and provided evidence that melody may exert dominant effects, at least in the spiral ganglion. The development of an in vivo model of the cysteine 163 mutation should enhance our understanding of the action of Caspase 3. In particular, given the potential for this mutant to bind and sequester proteins, it will be interesting to undertake a more comprehensive phenotype analysis of this mutant across a range of tissues in both heterozygote and homozygote mice; these experiments are underway.

Acknowledgments We thank Anne Southwell, Debra Brooker, Hilda Tateossian, Stuart Townsend, Tim Randall, Lucie Vizor, and Sara Wells for their technical support. We also thank Jenny Corrigan, Adele Seymour, and Caroline Barker from the histology department at MRC Harwell. This work was supported by the Medical Research Council and FP6 Integrated Project EuroHear, LSHG-CT-2004512063 .

Open Access This article is distributed under the terms of the Creative Commons Attribution Noncommercial License which permits any noncommercial use, distribution, and reproduction in any medium, provided the original author(s) and source are credited. 


\section{References}

Bose K, Clark AC (2005) pH effects on the stability and dimerization of procaspase-3. Protein Sci 14:24-36

Brown SD, Chambon P, de Angelis MH (2005) EMPReSS: standardized phenotype screens for functional annotation of the mouse genome. Nat Genet 37:1155

Brown SD, Hardisty-Hughes RE, Mburu P (2008) Quiet as a mouse: dissecting the molecular and genetic basis of hearing. Nat Rev Genet 9:277-290

Cohen GM (1997) Caspases: the executioners of apoptosis. Biochem J 326(Pt 1):1-16

Dejosez M, Krumenacker JS, Zitur LJ, Passeri M, Chu LF et al (2008) Ronin is essential for embryogenesis and the pluripotency of mouse embryonic stem cells. Cell 133:1162-1174

Earnshaw WC, Martins LM, Kaufmann SH (1999) Mammalian caspases: structure, activation, substrates, and functions during apoptosis. Annu Rev Biochem 68:383-424

Feeney B, Clark AC (2005) Reassembly of active caspase-3 is facilitated by the propeptide. J Biol Chem 280:39772-39785

Gu Y, Wu J, Faucheu C, Lalanne JL, Diu A et al (1995) Interleukin-1 beta converting enzyme requires oligomerization for activity of processed forms in vivo. EMBO J 14:1923-1931

Hardisty-Hughes RE, Parker A, Brown SD (2010) A hearing and vestibular phenotyping pipeline to identify mouse mutants with hearing impairment. Nat Protoc 5:177-190

Hrabe de Angelis MH, Flaswinkel H, Fuchs H, Rathkolb B, Soewarto $\mathrm{D}$ et al (2000) Genome-wide large-scale production of mutant mice by ENU mutagenesis. Nat Genet 25:444-447

Hunter-Duvar IM (1978) A technique for preparation of cochlear specimens for assessment with the scanning electron microscope. Acta Otolaryngol Suppl 351:3-23

Janicke RU, Ng P, Sprengart ML, Porter AG (1998) Caspase-3 is required for alpha-fodrin cleavage but dispensable for cleavage of other death substrates in apoptosis. J Biol Chem 273: $15540-15545$
Justice MJ, Noveroske JK, Weber JS, Zheng B, Bradley A (1999) Mouse ENU mutagenesis. Hum Mol Genet 8:1955-1963

Kang HJ, Lee YM, Jeong YJ, Park K, Jang M et al (2008) Large-scale preparation of active caspase-3 in E. coli by designing its thrombin-activatable precursors. BMC Biotechnol 8:92

Kuida K, Zheng TS, Na S, Kuan C, Yang D et al (1996) Decreased apoptosis in the brain and premature lethality in CPP32-deficient mice. Nature 384:368-372

Lavrik IN, Golks A, Krammer PH (2005) Caspases: pharmacological manipulation of cell death. J Clin Invest 115:2665-2672

Morishita H, Makishima T, Kaneko C, Lee YS, Segil N et al (2001) Deafness due to degeneration of cochlear neurons in caspase-3deficient mice. Biochem Biophys Res Commun 284:142-149

Nath R, Raser KJ, Stafford D, Hajimohammadreza I, Posner A et al (1996) Non-erythroid alpha-spectrin breakdown by calpain and interleukin 1 beta-converting-enzyme-like protease(s) in apoptotic cells: contributory roles of both protease families in neuronal apoptosis. Biochem J 319(Pt 3):683-690

Nicholson DW (1999) Caspase structure, proteolytic substrates, and function during apoptotic cell death. Cell Death Differ 6:1028-1042

Nolan PM, Peters J, Vizor L, Strivens M, Washbourne R et al (2000) Implementation of a large-scale ENU mutagenesis program: towards increasing the mouse mutant resource. Mamm Genome 11:500-506

Takahashi K, Kamiya K, Urase K, Suga M, Takizawa T et al (2001) Caspase-3-deficiency induces hyperplasia of supporting cells and degeneration of sensory cells resulting in the hearing loss. Brain Res 894:359-367

Van Criekinge W, Beyaert R, Van de Craen M, Vandenabeele P, Schotte $P$ et al (1996) Functional characterization of the prodomain of interleukin-1 beta-converting enzyme. J Biol Chem 271:27245-27248

Wang KK (2000) Calpain and caspase: can you tell the difference? Trends Neurosci 23:20-26 